\title{
Compound C Reducing Interferon Expression by Inhibiting cGAMP Accumulation
}

\author{
Junzhong Lai ${ }^{1,2 \dagger}$, Xuan Luo ${ }^{1,2 \dagger}$, Shuoran Tian ${ }^{1,2}$, Xing Zhang ${ }^{1,2}$, Shanlu Huang ${ }^{1,2}$, \\ Hanze Wang ${ }^{1,2}$, Qiumei $\mathrm{Li}^{1,2}$, Shaoli Cai ${ }^{1,2}$ and Qi Chen ${ }^{1,2 *}$ \\ 1 Fujian Key Laboratory of Innate Immune Biology, Biomedical Research Center of South China, Fujian Normal University \\ Qishan Campus, Fuzhou, China, ${ }^{2}$ College of Life Science, Fujian Normal University Qishan Campus, Fuzhou, China
}

Cyclic GMP-AMP (cGAMP) synthase (cGAS) is a major DNA sensor responsible for cytosolic DNA-mediated innate immune response. Inhibition of cGAS may be an effective strategy for treating autoimmune diseases such as Aicardi-Goutieres syndrome and systemic lupus erythematosus. Compound C (also known as Dorsomorphin) has been annotated as a potent and reversible inhibitor for AMPKs as well as ALK protein kinases. Here, we report a new function of Compound $\mathrm{C}$ which can suppress dsDNA-dependent type I interferon induction. These effects were not dependent on the activities of AMPK proteins. In vitro assays and liquid chromatograph-mass spectrometry data show that Compound $\mathrm{C}$ has the capability of reducing cGAMP accumulation, suggesting that Compound $\mathrm{C}$ may function as a modulator involved in the cGAS-STING-mediated DNA sensing pathway. Furthermore, Compound $C$ is able to rescue the autoimmune phenotypes in a mouse model carrying the Trex1 gene deficiency. These data demonstrate a new and inverse correlation between Compound $\mathrm{C}$ and type I interferon production in response to dsDNA signaling.

Keywords: compound C, dorsomorphin, cGAS, cGAMP, DNA sensing, type I interferon

\section{INTRODUCTION}

Innate immune response represents a fundamental ability of host-defense in dealing with pathogen invasion or endogenous tissue injury (Takeuchi and Akira, 2010). DNA, as a dangerous immune stimulant, can be derived from a large variety of sources, including invading microbes and selfdestructive cells, and trigger host innate immune response (O'Neill et al., 2013). Recognition, clearance, and signaling of these dangerous DNAs play a pivotal role in host defense and human health (Goubau et al., 2013; Wu and Chen, 2014; Pandey et al., 2015). Cyclic GMP-AMP (cGAMP) synthase (cGAS) has been discovered as a major DNA sensor that recognizes the dangerous DNAs present in the cytoplasm and is responsible for cytosolic DNA-mediated immune responses leading to the production of type-I interferons (IFNs) and other inflammatory cytokines. cGAS binds Bform DNA in a sequence-independent manner (Xiao and Fitzgerald, 2013; Cai et al., 2014; Wu and Chen, 2014), and is considered to contribute as a nonredundant and dominant cytosolic DNA sensor (Li et al., 2013; Schoggins et al., 2014). DNA binding causes the activation of cGAS, catalyzing the synthesis of non-canonical 2'-5' cGAMP (Ablasser et al., 2013; Civril et al., 2013; 
Diner et al., 2013; Gao et al., 2013; Kranzusch et al., 2013; Li et al., 2013; Zhang et al., 2013; Abe and Barber, 2014; Zhang et al., 2014). Then, cGAMP acting as a second messenger to stimulate the adaptor protein STING, along with STING rapidly traffics with TBK1 via VPS34-related autophagosomes to associate with endosomal compartments containing NF- $\mathrm{\kappa B}$ and IRF3 (Ishikawa and Barber, 2009; Abe et al., 2013), and triggers the production of numerous cytokines and chemokines responsible for innate immune response.

Due to the significant role of cGAS in innate immunity, smallmolecule inhibitors of cGAS may be used not only for further exploring cGAS-mediated DNA sensing mechanisms and innate immunity regulation, but also for treatments of autoimmune disorders (Vincent et al., 2017). Recently, small molecules such as RU.521 and RU.365 have been found to bind to the catalytic pocket of cGAS and inhibit its dsDNA-stimulated activity. Unfortunately, RU.521 only showed the effect in a cellular assay, but not in the in vivo tests (Vincent et al., 2017). PF06928215, a high affinity inhibitor of human cGAS activity (IC50 $=4.9 \mu \mathrm{M}$ ), displayed no activity in cellular cGAS assays when measuring dsDNA-induced IFN- $\beta$ expression (Hall et al., 2017). In addition, Suramin has been identified as a new cGAS inhibitor, but its activity needs to be further validated (Wang et al., 2018b). Thus, it is a daunting challenge to discover the better cGAS inhibitors both in vivo and in vitro.

The previous publication demonstrated that STING is activated by UNC-51-like kinase (ULK1)-mediated phosphorylation, which occurs following ULK1 dissociation from its repressor, AMPactivated protein kinase (AMPK), and inhibition of AMPK by compound C substantiated ULK1-mediated STING phosphorylation and activation (Konno et al., 2013).

Compound $\mathrm{C}$ is a small molecule compound commonly used as an inhibitor of AMPK which is the key energy sensor in cells (Zhou et al., 2001; Jin et al., 2009). However, Compound C has been shown to exert various AMPK-independent effects in different cell types (Seo et al., 2016). For example, treatment of MCF7 cells by Compound C leads to Bax redistribution from the cytoplasm to mitochondria and cell death (Jin et al., 2009), and Compound C increases Sestrin2 expression via mitochondriadependent ROS production (Seo et al., 2016). Compound C prevents the AMPK signaling-independent unfolded protein response during glucose deprivation (Saito et al., 2012). Compound C inhibits ICAM-1 and VCAM-1 expression in inflammatory stimulants-activated endothelial cells (Kim et al., 2011). In accordance with these discoveries, Compound $C$ has been found to inhibit many other kinases in addition to AMPK in several kinase profiling studies and is thus highly non-specific (Dasgupta and Seibel, 2018).

In this study, the important role of Compound $\mathrm{C}$ related to innate immunity was investigated. We found that Compound $\mathrm{C}$ could largely inhibit type I interferon production induced by foreign DNAs, but not by cGAMP. Compound C mediated DNA-induced IFN inhibition might occur in the upstream of cGAMP and reveal a new functional role of Compound $\mathrm{C}$ in addition to its existing inhibitory activities in many kinasesinvolved signaling pathways.

\section{MATERIALS AND METHODS}

\section{Cell Culture and Transfection}

L929, BJ, THP1, and 293T cell were cultured in an atmosphere of $5 \% \mathrm{CO}_{2}$ in RPMI-1640 or DMEM medium supplemented with $10 \%$ fetal bovine serum (FBS). THP1-lucia-IFN $\beta$-ISG was purchased from Invivogen (California, USA) and cultured in an atmosphere of $5 \% \mathrm{CO}_{2}$ in RPMI-1640 medium supplemented with $10 \%$ FBS after $55^{\circ} \mathrm{C}$ inactivated.

Transfection of HT-DNA (Sigma, St. Louis, Missouri, USA) and plasmid DNA (pcDNA-3.1-TBK1-Flag) into cells were performed by mixing $2 \mu \mathrm{g}$ DNA with $6 \mu \mathrm{l}$ Lipofectamine 2000 (Invitrogen, California, USA). cGAMP (Biolog, Flughafendamm, German) stimulation assay was performed as previously described (Wu et al., 2013). Briefly, cells were incubated at $37^{\circ} \mathrm{C}$ for $30 \mathrm{~min}$ with cGAMP in permeabilization buffer (50 mM HEPES, pH 7; $100 \mathrm{mM} \mathrm{KCl;} 3 \mathrm{mM} \mathrm{MgCl}_{2} ; 0.1$ mM DTT; 85 mM sucrose; 0.2\% BSA; 1 mM ATP, 0.1 mM GTP and $1 \mu \mathrm{g}$ ml-1 digitonin). Then, the permeabilization buffer was replaced with complete medium and cells were cultured for the indicated time.

\section{Mouse Embryonic Fibroblast Culture}

The $\mathrm{Trex}^{-/-}$mouse line was obtained from the Jackson Laboratories (Cambridge, MA, USA). All mice were maintained under pathogen-free conditions and housed in a temperature $\left(22^{\circ} \mathrm{C} \pm 2^{\circ} \mathrm{C}\right)$ and humidity controlled environment on a 12-h light/dark cycle with free access to food and water. The animal experiments were performed under the Guide for the Care and Use of Laboratory Animals approved by Fujian Provincial Office for Managing Laboratory Animals and were overseen by the Fujian Normal University Animal Care and Use Committee.

Primary MEFs were isolated from embryonic day 13.5 (E13.5) embryos of wild type and Trex $1^{-/-}$mice. MEFs were cultured in the DMEM supplemented with $10 \%$ FBS with the addition of 100 $\mathrm{U} / \mathrm{ml}$ penicillin and $100 \mathrm{mg} / \mathrm{ml}$ streptomycin and under the culture condition that includes $37^{\circ} \mathrm{C}$ with $5 \% \mathrm{CO}_{2}$.

\section{Cell Viability Assay}

Cell were seeded into 96-well plates at a density of $5 \times 10^{4}$ cells per well and incubated with Compound C (the purity is $99.82 \%$ and purchased from Selleck, Shanghai, China) at the indicated concentration for $24 \mathrm{~h}$. The cell viability was analyzed with CCK8 (TransGen Biotech, Beijing, China) according to the manufacturer's instruction.

\section{RNA Isolation, Reverse Transcription (RT), and Real-Time Quantitative Polymerase Chain Reaction (qPCR)}

Total RNA was extracted from cells with Trizol (TAKARA, Dalian, China) according to the manufacturer's instruction. The RT reaction was performed using $1 \mu \mathrm{g}$ of total RNA with PrimeScript ${ }^{\circledR}$ RT reagent Kit plus gDNA Eraser (TAKARA, Dalian, China).

The mRNA expression levels of different genes were quantified by the real-time quantitative RT PCR (RT-qPCR) using SYBR ${ }^{\circledR}$ 
Premix Ex Taq II (Tli RNaseH Plus) (TAKARA, Dalian, China) at $95^{\circ} \mathrm{C}$ for $30 \mathrm{~s}$, followed by 40 cycles of $95^{\circ} \mathrm{C} 5 \mathrm{~s}, 60^{\circ} \mathrm{C} 20 \mathrm{~s}$, and $72^{\circ} \mathrm{C}$ $30 \mathrm{~s}$. The PCR was performed on QuantStudio ${ }^{\mathrm{TM}} 6$ Flex Fast realtime PCR system (Applied Biosystems, Carlifornia, USA), and the relative expression level was calculated by using the $2^{-\triangle \triangle C T}$ method. The primer sequences for related genes are shown in Table $\mathbf{S 1}$ of supplementary materials.

\section{Generation of Gene Knockout Cell Lines via CRISPR/Cas9}

The sgRNA oligo sequences for their respective target genes are as follows: m-AMPK $\alpha 1$ : 5'-CGAGTTGACCGGACATAAAG; m-AMPK $\alpha 2$ : 5'-CCTGAAGCGAGCGACTATCA; H-STING: 5'-GGTGCCTGATAACCTGAGT. The sgRNA sequences were annealed and cloned into the vector PX459. To delete target genes, L929 and THP1 cells were transiently transfected with the PX459 plasmids carrying the respective sgRNAs, and selected with $1 \mu \mathrm{g} / \mathrm{ml}$ puromycin for 2 days. Cells were then cultured in complete medium without puromycin and seeded at a low density to allow colony formation from single cells. Colonies were then picked and expanded for knock-out validation by sequencing of target genomic region, immunoblotting or ELISA.

\section{Western Blot Analysis and ELISA}

The cells with the various treatments were washed with ice-cold PBS, harvested by gentle scraping, and lysed with ice-cold RIPA cell lysis buffer (25 mM Tris $\bullet \mathrm{HCl}$ pH 7.6, $150 \mathrm{mM} \mathrm{NaCl}, 1 \% \mathrm{NP}-$ $40,1 \%$ sodium deoxycholate, $0.1 \%$ SDS). Total protein amount was determined by BCA protein determination method. Forty microgram of the protein samples were electrophorased on $10 \%$ Tricine-SDS-polyacrylamide gels and transferred to polyvinylidene difluoride membranes for hybridization with the corresponding primary antibodies, followed by IRDye $800 \mathrm{CW}$ or $680 \mathrm{LT}$ secondary antibodies $(1: 1,000)$ and visualized by Odyssey CLx Western Blot Detection System (Westburg, Leusden, Netherlands). The expression of GAPDH was used as the endogenous control. The level of IFN $\beta$ production was measured by ELISA according to manufacturer's instructions of mouse IFN $\beta$ bioluminescent ELISA kit (Invivogen, Carlifornia, USA).

\section{Preparation of S100 Cytoplasmic Extracts}

The BJ cells $\left(1 \times 10^{6}\right.$ cells per $10 \mathrm{~cm}^{2}$ flask) were treated with DMSO or the various concentrations of Compound C $(3 \mu \mathrm{M}, 5 \mu \mathrm{M}, 10$ $\mu \mathrm{M}, 20 \mu \mathrm{M})$ for $1 \mathrm{~h}$. Then, the cells were treated with or without HT-DNA for 6 hours and the cytoplasmic extracts (S100) were prepared as follows: the attached cells were firstly soaked in hypotonic buffer (10 mM Tris- $\mathrm{HCl}, \mathrm{pH} 7.4,10 \mathrm{mM} \mathrm{KCl}, 1.5 \mathrm{mM}$ $\left.\mathrm{MgCl}_{2}\right)$. Then, the cells were scraped down and centrifuged at $14,000 \mathrm{~g}$ for $10 \mathrm{~min}$. The supernatant was collected and heated at $95^{\circ} \mathrm{C}$ for $5 \mathrm{~min}$. Finally, the cell lysate mixtures were centrifuged at $14,000 \mathrm{~g}$ for $8 \mathrm{~min}$, and the supernatant was collected, designated as the cytoplasmic extract (S100). The cytosolic extracts from mock or HT-DNA-transfected cells were then permeabilized by incubating with PFO in THP1-Lucifrase cells and the expression of IFN $\beta$ was analyzed by RT-qPCR.

\section{In Vitro cGAMP Synthesis Assay}

The cGAS enzyme activity detection mixture was prepared as follows: $1 \mathrm{mg} / \mathrm{ml}$ HT-DNA, purified recombinant mouse and human cGAS protein (the cGAS expression vector was constructed in our laboratory), $10 \times$ buffer (200 mM Tris-Cl, 50 $\mathrm{mM} \mathrm{MgCl} 2$, pH7.5) ,0.1 $\mathrm{M} \mathrm{CoCl}_{2}, 100 \mu \mathrm{M}$ ATP, $100 \mu \mathrm{M}$ GTP). Then the mixture was aliquoted and incubated with various concentrations of Compound $\mathrm{C}$ at $37^{\circ} \mathrm{C}$ for $30 \mathrm{~min}$. Finally, the ATP of reaction mixture was detected by ATP Assay Kit.

\section{cGAMP Quantitative Analysis by LC/MS}

cGAMP was extracted and purified from BJ cell treated with Compound $\mathrm{C}$, and the quantity of cGAMP was detected by mass spectrometry. Cell extracts were obtained by using $20 \%$ (vol/vol) methanol and $2 \%$ acetic acid solution after transfected with HTDNA for 6 hours. cGAMP labeled with 13C1015N5 was added as the homogenized control. Then, cGAMP of the cell extracts was enriched by using the HyperSep Aminopropyl SPE column and the eluent was dried by rotary vacuum and redissolved in liquid chromatography (LC)/MS grade water. Finally, the enriched cGAMP was transferred to the automatic sampler vials of the liquid chromatograph/mass spectrometer for mass spectrometry analysis as follows.

The SPE eluent was separated by Dionex Ultimate 3000 rapid liquid chromatography system (Thermo Scientific, Massachusetts, USA), using Xbirdgy Amide column $(3.5 \mu \mathrm{M}$, inner diameter $3.5 \mathrm{~mm} \times 100 \mathrm{~mm}$, Waters). The mobile phase A was $20 \mathrm{mM}$ ammonium bicarbonate aqueous solution containing $20 \mathrm{mM}$ ammonium hydroxide, and the mobile phase B was acetonitrile. The first separation velocity was 400 $\mathrm{ml} / \mathrm{min}$ and the time was $14.5 \mathrm{~min}$. The flow rate was $800 \mathrm{ml} /$ min and the time was $8.5 \mathrm{~min}$. The gradient elution process was: $85 \%$ B 0 min, $85 \%$ B 3 minutes; 2\% B 10 min; 2\% B 14 min; 85\% B $14.5 \mathrm{~min}$; and 85\% B $23 \mathrm{~min}$.

The LC eluent collected by liquid chromatography was ionized by Ion Max NG heating electrospray source, and the spray voltage was $3,750 \mathrm{~V}$. Ion transfer tube temperature was $342^{\circ} \mathrm{C}$, gasification temperature was $292^{\circ} \mathrm{C}$. The spray was analyzed by TSQ Quantiva triple quadruplet mass spectrometer (Thermo Scientific, Massachusetts, USA), where the continuous multireaction monitoring scanning residence time was $50 \mathrm{~ms}$, the resolution of Q1 and Q3 was 0.7 FWHM, and the collision decomposition gas was 1.5 units. cGAMP and the previously standard cGAMP which was labeled 13C1015N5 were monitored by four transformations respectively in the positive mode (cGAMP: 675-136, 675-152 675-476, and 675524; Internal standards: 691-146, 691-152, 691-491, and 691539). The original mass spectrum data would be converted into the mzXML format with ReAdW and read into MATLAB software for noise reduction and data analysis. The absolute amount of cGAMP standard labeled 13C1015N5 was used as a reference to calculate the absolute amount of cGAMP to be tested, so as to obtain the amount of cGAMP contained in the same amount of cells under different conditions. 


\section{RESULTS}

\section{Compound C Inhibits Type I IFN Production Induced by dsDNA Signaling}

Compound $\mathrm{C}$ is annotated as an AMPK inhibitor and can affect DNA-induced IFN $\beta$ expression (Konno et al., 2013). However, this effect might not involve its anti-AMPK activities due to its multidimensional antikinase activities.
We conducted the following studies to address this question. To rule out a possible cytotoxic effect caused by Compound C, we first tested the cell viability by CCK-8 assays (Figure 1A). The L929 cell viability was affected by the concentration increment and was dropped by $20 \%$ and more than $50 \%$ after treatments with 20 and $40 \mu \mathrm{M}$ Compound C for $24 \mathrm{~h}$, respectively. The inhibitory effect of Compound $\mathrm{C}$ on AMPK activities was also tested by examining the AMPK

A

L929

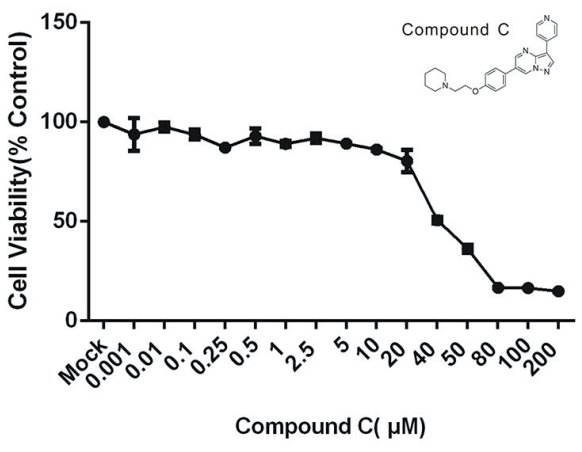

B

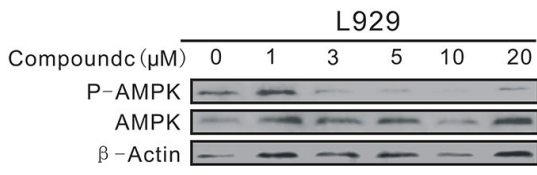

D

L929

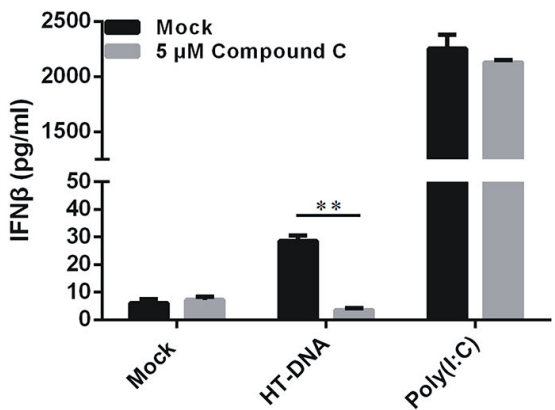

L929

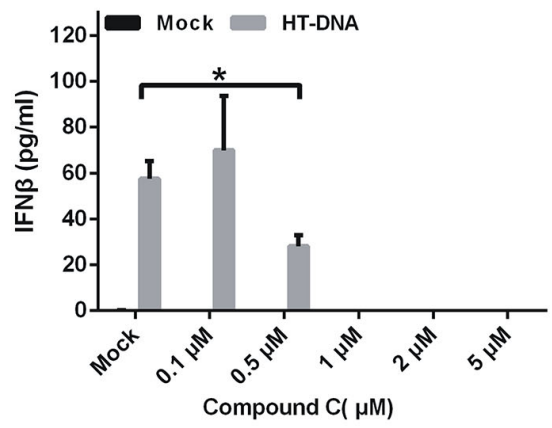

E

BJ

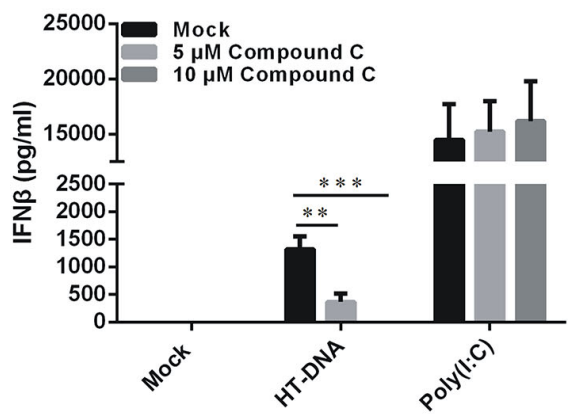

FIGURE 1 | Compound C inhibited type I IFN production in dsDNA signaling. (A) L929 cells were treated with the different doses of Compound C for $24 \mathrm{~h}$, and subjected to the CCK-8 assay. (B) Compound C inhibited the AMP-activated protein kinase (AMPK) activity as tested by Western blotting. (C) Enzyme-Linked Immunosorbent Assay (ELISA) analyses of IFN $\beta$ expression in L929 cells. The cells were transfected with HT-DNA after treated with the different doses of Compound C for 1 h. (D, E) ELISA analyses of IFN $\beta$ expression in L929 and BJ cells. The cells were transfected with HT-DNA and poly (I:C) after treated with indicate doses of Compound $\mathrm{C}$. The experiments were performed at least three times. The statistical analyses were performed by Student's- $t$ test and the data are presented as mean $\pm \mathrm{SD}\left(\mathrm{n}=3,{ }^{\star} P<0.05,{ }^{\star \star} P<0.01,{ }^{\star \star \star} P<0.001\right)$ 
phosphorylation levels. The AMPK phosphorylation was significantly affected by Compound $\mathrm{C}$ at the concentration larger than $3 \mu \mathrm{M}$ (Figure 1B). Consistent with the previous findings (Konno et al., 2013), our Enzyme-Linked Immunosorbent Assay (ELISA) data showed that the HTDNA-induced IFN $\beta$ production was significantly suppressed in both L929 and BJ cells by Compound C (Figures 1C-E). In contrast, the IFN $\beta$ production induced by the RNA surrogate polyinosinic-polycytidylic acid (poly(I:C)) was not significantly affected in these cell types (Figures 1D-E) (Konno et al., 2013). To exclude the possible effect due to the high working concentrations of poly(I:C) stimulation, we also titrated down the doses to obtain responses equivalent in magnitude to those elicited by HT-DNA. However, it turned out that Compound $\mathrm{C}$ did not inhibit the RNA-mediated IFN $\beta$ production at any concentration tested (Figure S1A). These data suggest that Compound $\mathrm{C}$ specifically affects DNA-mediated IFN $\beta$ production in these cell types.

\section{Compound C Does Not Affect cGAMP- Mediated IFN $\beta$ Expression}

We next examined the Compound C effects on the cGAS-STING pathway which regulates DNA-dependent IFN $\beta$ induction. Our RT-qPCR data showed that Compound C significantly suppressed the IFN $\beta$ RNA expression-induced by HT-DNA in various cell types including BJ, L929, and THP-1 cells (Figures 2A, C, E), but not by cGAMP which was delivered by digitonin permeabilisation. (Figures 2B, D, F). Because a recent discovery suggests that the extarcellular cGAMP can be taken up directly by cells via the transporter SLC19A1 (Luteijn et al., 2019), we also tested the Commpoun $\mathrm{C}$ effect by adding cGAMP to the medium without digitonin permeabilisation. We also did not observe the Compound $\mathrm{C}$ effect on cGAMP-mediated IFN $\beta$ expression (Figure 6B). Next, we examined the Compound $\mathrm{C}$ effects on the activities of the regulatory components downstream of cGAMP by Western blotting. Activation of the cGAS-STING pathway is indicated by the phosphorylation of STING and TBK1. In parallel to the above RT-qPCR data, HTDNA-induced STING and TBK1 protein phosphorylation was significantly inhibited by Compound C (Figure 2G) whereas cGAMP and poly(I:C)-induced STING and TBK1 phosphorylation was not affected (Figure 2G). We also titrate down the concentrations, but still did not see any effect (Figure S1B). Again, these data indicate that Compound $\mathrm{C}$ can inhibit cGAS-STING signaling initiated by DNA, and the target site of Compound $\mathrm{C}$ is likely to be located upstream of cGAMP.

\section{Compound C Inhibition on the dsDNA- Dependent Pathway is not Related to its Inhibitory Function on the AMPK Activity}

Since Compound $\mathrm{C}$ is a potent inhibitor of AMPK, we asked if AMPK $\alpha$ was involved in the inhibitory effects of Compound $\mathrm{C}$ on DNA-mediated cGAS-STING signaling. We disabled AMPK $\alpha 1$ and $\alpha 2$ genes in L929 cells by using the CRISPR/Cas 9 gene editing system and established the corresponding gene knockout cell lines, and then studied the effects of Compound C on DNA-induced IFN $\beta$ and Cxcl10. Lack of AMPK expression was shown in Figure 3A and its expression was not affected by either HT-DNA or poly (I:C) treatments. The induction of IFN $\beta$ by HT-DNA did not seem to be affected by AMPK gene knockout and was suppressed by Compound C in both L929 and L929-AMPK ${ }^{-/-}$cell lines (Figure 3B), but Compound C did not affect in poly (I:C)-induced IFN $\beta$ (Figure 3C). These data suggest that the inhibitory effect of Compound C on DNAinduced IFN $\beta$ expression is not dependent on the activity of AMPK (Figure 3A). In agreement with the previous studies, AMPK knockout was able to facilitate both HT-DNA and cGAMP-induced IFN $\beta$ and CXCL10 mRNA expression (Figures 3D, E). However, the deficiency of AMPK has no effect on the dsRNA-dependent pathway (Figure 3F). Thereby, the Compound $\mathrm{C}$ effects on the dsDNA-dependent pathway are not due to its inhibition of AMPK function.

\section{The Target of Compound $\mathrm{C}$ was in the Upstream of TBK1}

TBK1 is the downstream protein kinase that drives both DNAand RNA-mediated production of type I IFN by phosphorylating the transcription factor interferon regulatory factor 3 (IRF3) (Liu et al., 2015). To locate the target of the Compound $\mathrm{C}$ action, we performed overexpression of TBK1 to activate the expression of IFN $\beta$ in THP1 and THP1-STING ${ }^{-/-}$ cells. As indicated earlier, STING is the immediate upstream adaptor protein that regulates TBK1 activation ( $\mathrm{Wu}$ et al., 2013). IFN $\beta$ was induced by TBK1 overexpression but was dependent on the presence of STING (Figures 4A, B). We found that the expression of IFN $\beta$ was significantly reduced after $1 \mathrm{~h}$ treatment of the THP1 cell line with $5 \mu \mathrm{M}$ Compound C following HT-DNA and pcDNA3.1-TBK1 transfection, while no effect on the THP1-STING ${ }^{-/-}$cell line was found (Figures $\mathbf{4 A}, \mathrm{B})$. So we assumed that the target of Compound $\mathrm{C}$ in suppressing dsDNA-dependent IFN $\beta$ was in the upstream of TBK1. To further address this issue, we overexpressed TBK1 in $293 \mathrm{~T}$ cell line in which little cGAS or STING is expressed (Figure 4C), and then treated these cells with Compound C. Compound $\mathrm{C}$ lost its capability to suppress IRF3 activation when TBK1 was overexpressed (Figure 4D). Furthermore, Compound $\mathrm{C}$ did not inhibit the expression of IFN $\beta$ and ISG56 after TBK1 overexpression (Figures 4D, E). Therefore, the target of Compound $\mathrm{C}$ on dsDNA-signaling is likely to be located in the upstream of TBK1.

\section{Compound C Lowers the Level of cGAMP}

To evaluate the Compound $\mathrm{C}$ effect on the cGAMP level, we treated BJ cells with combined HT-DNA and Compound C (at various concentrations) and the cytoplasmic extract (S100), which supposed to contain the endogenous cGAMP, was isolated and used to treat THP-Luci cells to induce the IFN $\beta$ production. Commercially purchased cGAMP was also used as control (Figure 5A). The RT-qPCR data show that the mRNA levels of IFN $\beta$ induced by the $\mathrm{S} 100$-fraction were largely reduced in the THP1-luci-ISG cell line by Compound $\mathrm{C}$ at the concentrations higher than $5 \mu \mathrm{M}$, suggesting that 
A

L929

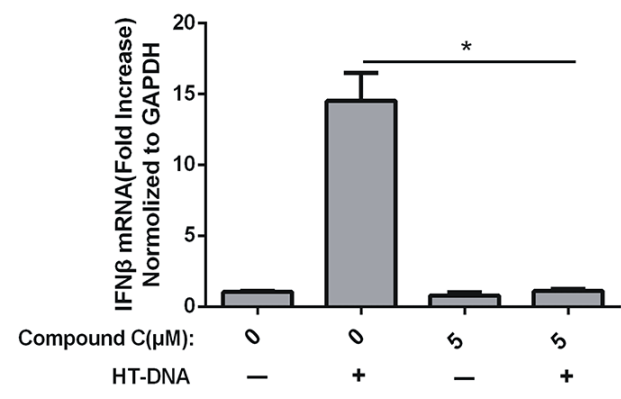

BJ

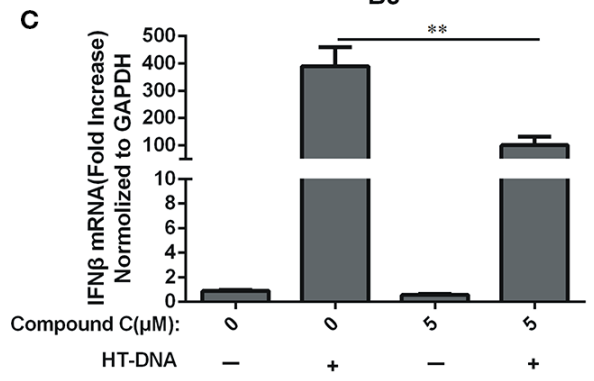

E

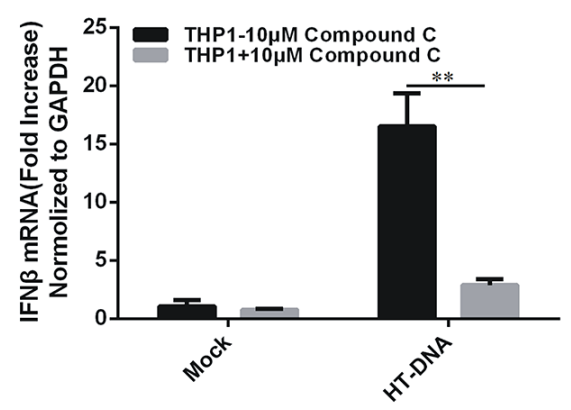

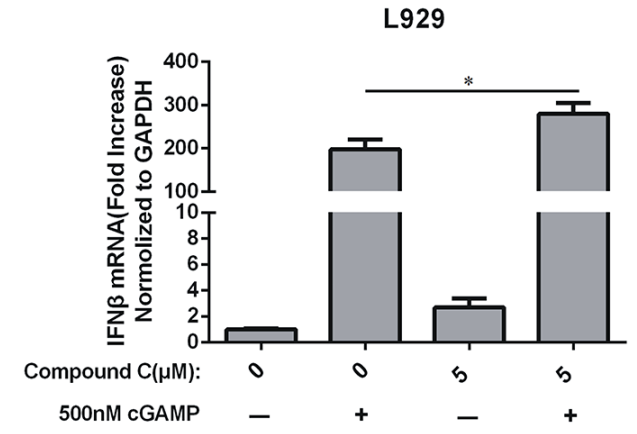

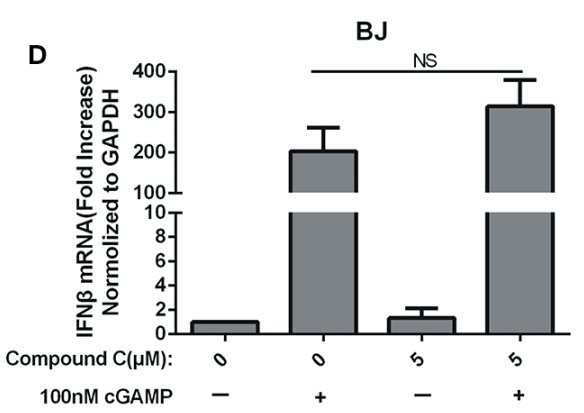

F

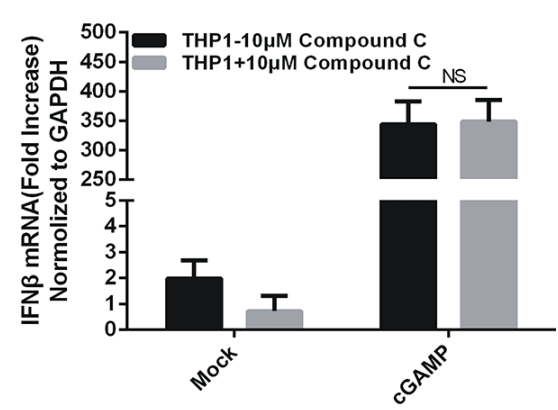

G

BJ

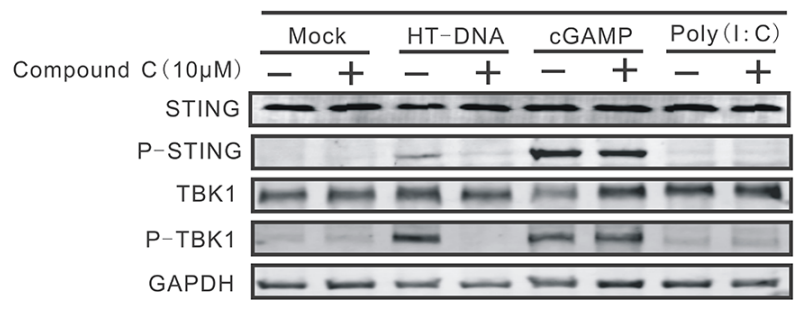

FIGURE 2 | Compound C suppressed the expression of IFN $\beta$ by transfected dsDNA, but not CGAMP. (A, C, E) RT-qPCR analyses of IFN $\beta$ expression in L929 (A), BJ (C), THP1 (E) cells. The cells were transfected with HT-DNA after treated with indicated doses of Compound C. (B, D, F) RT-qPCR analyses of IFN $\beta$ expression in L929 (B), BJ (D), THP1 (F) cells. The cells were transfected with poly (I:C) after treated with indicated doses of Compound C for 1 h. (G) Western blot analyses of STING, P-STING, TBK1, P-TBK1, and GAPDH expression in BJ cells. The cell was transfected with HT-DNA, cGAMP and poly (I:C) after treated with indicate doses of Compound C. The experiments were performed at least three times. Data in bar graphs are presented as mean $\pm S D(n=3-5)$ with asterisks indicating significant changes (NS Nonsignificance, ${ }^{\star} P<0.05,{ }^{\star \star} P<0.01$ ).

Compound C strongly lowered the cGAMP level (Figures 5B, C). In addition to IFN $\beta$, the mRNA expression of CXCL10 was also inhibited in the presence of Compound C (Figure 5D). To more directly assess the level of cGAMP, we measured the
cGAMP content in the S100 extracts collected from BJ cells treated with HT-DNA or combined treated with Compound C by LC-MS. The data showed that Compound C significantly lowered HT-DNA-induced cGAMP level (Figures 5E, F). 

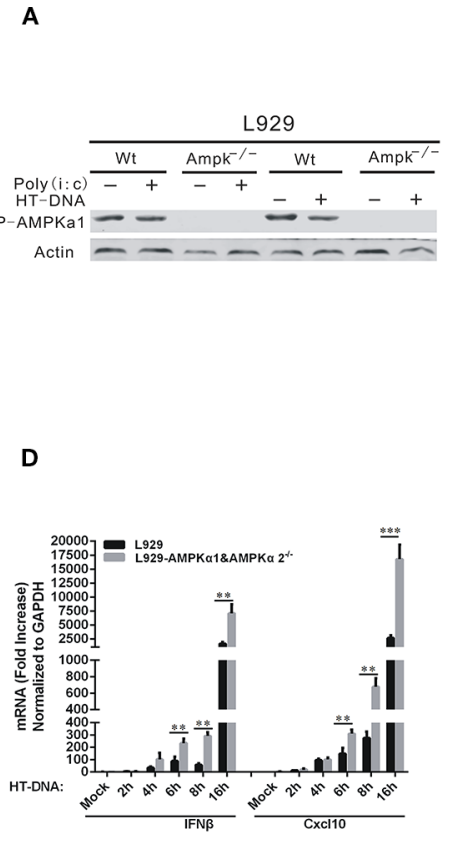

B
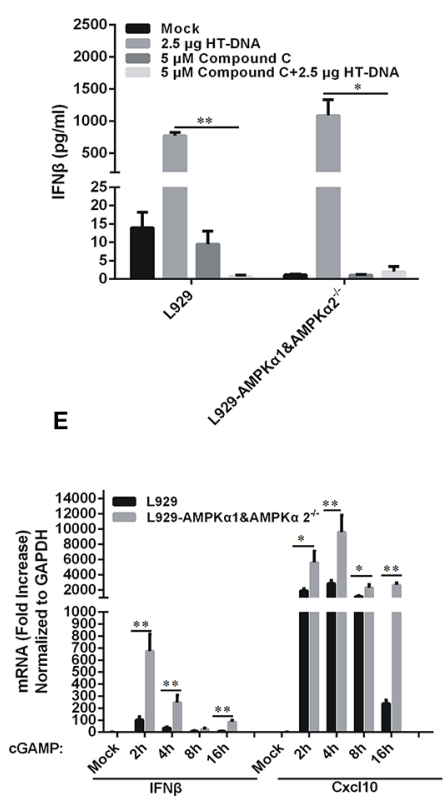
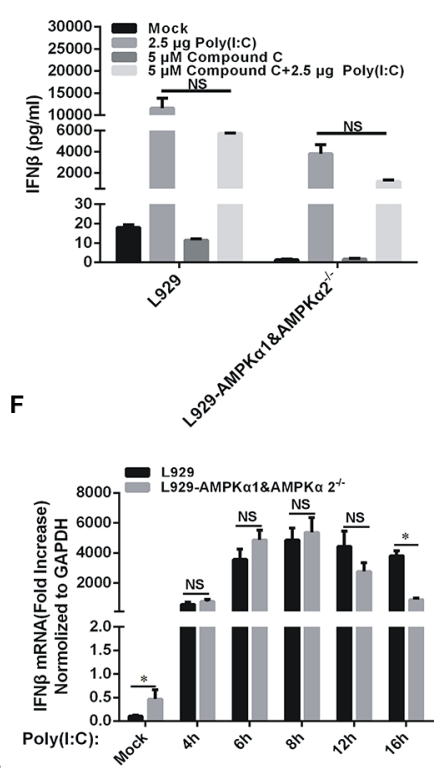

FIGURE 3 | Compound C inhibited the dsDNA-dependent pathway which was not dependent on the activity of AMP-activated protein kinases (AMPKs). (A) Western blot analyses of phorsphorylated AMPK in L929 wild-type and L929-AMPK ${ }^{-1}$ cells. The cells were transfected with HT-DNA and poly (I:C). (B, C) RT-qPCR analyses of IFN $\beta$ expression in L929 and L929-AMPK ${ }^{-1-}$ cells. The cells were transfected with HT-DNA (B) or poly (I:C) (C) after treated with indicated dose of Compound C. (D-F) RT-qPCR analyses of IFN $\beta$ and CXCL10 expression in L929 wild-type and L929-AMPK ${ }^{-1-}$ cells. The cells were transfected HT-DNA (D), cGAMP (E); Analyses of IFN 3 expression in L929 wild-type and L929-AMPK ${ }^{-1}$ cells. The cells were transfected with poly (I:C) (F). The experiments were performed at least three times. Data in bar graphs are presented as mean \pm SD $(n=5)$ with asterisks indicating significant changes between the indicated bars (NS, Nonsignificance, $\left.{ }^{*} P<0.05,{ }^{\star \star} P<0.01,{ }^{\star \star *} P<0.001\right)$.

These data suggest that Compound $\mathrm{C}$ is able to lower the cGAMP level.

\section{Compound C Does not Affect the cGAS Enzymatic Activity In Vitro}

Since the cGAMP level could be affected by cGAS-mediated synthesis, we tested the cGAS enzymatic activity. First, the expression levels of cGAS protein in L929 and L929-AMPK-KO cells were analyzed by Western blotting, and the data showed that the expression of cGAS protein was not affected by Compound C in both the wild type and AMPK gene knockout L929 cells (Figure 6A). We next asked if Compound $C$ could affect the cGAS enzymatic activity in vitro. We examined ATP consumption during the cGAMP synthesis in vitro, but did not see any effect (Figures 6C, D). Therefore, the suppression of Compound C on DNA-mediated cGAS-STING signaling activation is not affected by the cGAS enzymatic activity. We also aksed if Compound $\mathrm{C}$ could affect cGAMP transportation, We treated THP1-Luci cells by $5 \mu \mathrm{M}$ Compound $\mathrm{C}$ along with cGAMP at the high concentrations (at which cGAMP is supposed to be transported into cells (Luteijn et al., 2019) without digitonin permeabilisation for $16 \mathrm{~h}$, then cGAMP transshipment was examined by Multiscan Spectrum). In fact, we did not observe the Compound $\mathrm{C}$ effect on cGAMP transshipment (Figure 6B). Thus, Compound $\mathrm{C}$ does not affect cGAS enzymatic activity.

\section{Compound C Ameliorates Autoimmune Phenotypes Induced by Loss of Trex1 Gene In Vitro Cells}

TREX1 is a major cytoplasmic exonuclease that degrades dsDNA and ssDNA (Yun-Gui et al., 2007; Nan et al., 2010). The TREX1 gene Mutations have been linked to the autoimmune diseases including Aicardi-Goutières syndrome (AGS) and systemic lupus erythematosus (SLE) (Crow et al., 2006). The autoimmune phenotypes derived from the Trex 1 gene mutations in mice can be ameliorated by cGAS or STING gene knockout (Gao et al., 2015; Xiao et al., 2019). Since Compound C displays an inhibitory effect on the cGAS-STING-mediated pathway, we further determined its potential beneficial effects against autoimmune phenotypes in the Trex1 mutant cells. We isolated the mouse embryonic fibroblasts (MEFs) from the Trex1 knockout mice. Since the half-life of IFN $\beta$ is short and the detection time is not well established in MEF-Trex $1^{-1-}$, we examined downstream ISGs instead, but not IFN $\beta$ itself, to verify the Compound $C$ inhibitory effect on cGAS-STING activation caused by Trex 1 deletion. These cells displayed the elevated levels of CXCL10, ISG15, ISG56, and IFIT3 and their expression was significantly suppressed by Compound $\mathrm{C}$ (Figures 7A-D), suggesting the effectiveness of Compound $\mathrm{C}$ in inhibiting intrinsic DNA-dependent, constitutively activated type I IFN expression in the cells deficient in TREX1. Therefore, 
A

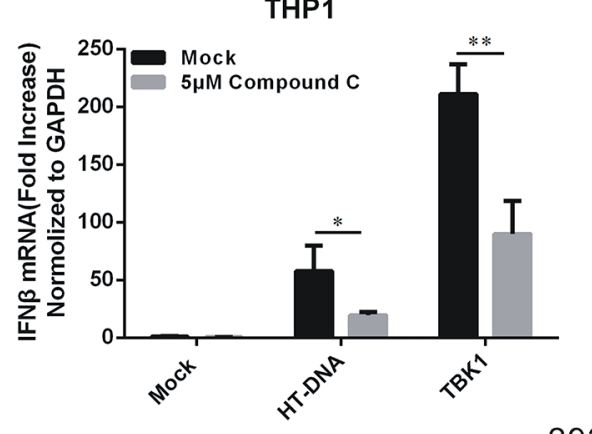

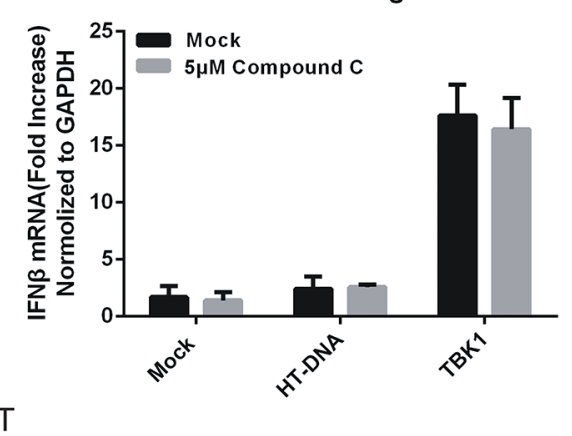

$10 \mu \mathrm{M}$ Compound C

C

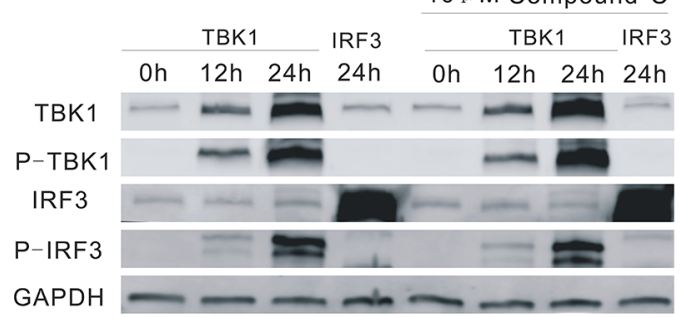

D

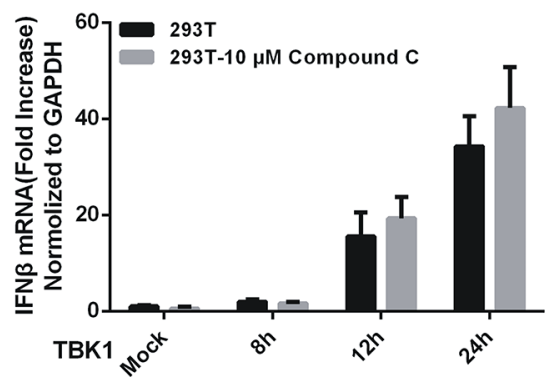

E

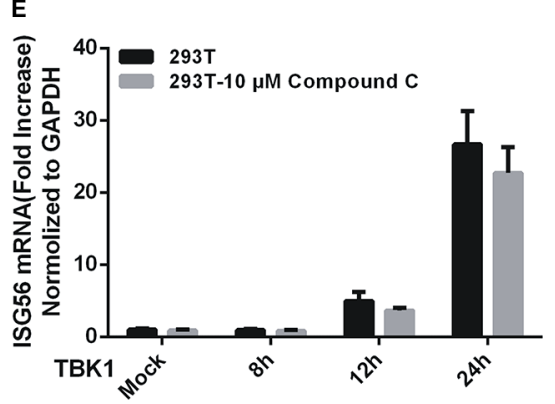

FIGURE 4 | The target of Compound $\mathrm{C}$ was in the upstream of TBK1. (A, B) RT-qPCR analyses of IFN $\beta$ expression levels in THP1 wild-type (A) and THP1-STING ${ }^{-1}$ (B) cells. The cells were transfected with HT-DNA and pcDNA 3.1-TBK1-Flag after treated with indicated dose of Compound C. (C) Western blot analyses of TBK1, p-TBK1, IRF3, and p-IRF3 expression in 293T cells. The 293T cells were treated with $10 \mu \mathrm{M}$ Compound C followed by transfection with pcDNA3.1-TBK1-Flag and pcDNA3.1-IRF3-Flag. (D, E) RT-qPCR analyses of IFN 3 (D) and ISG56 (E) expression in 293T cells. The 293T cells were treated with $10 \mu \mathrm{M}$ Compound C followed by transfection with pcDNA3.1-TBK1-Flag for $12 \mathrm{~h}$ and $24 \mathrm{~h}$, respectively. The experiments were performed at least three times. The statistical analyses were performed by Student's- $t$ test and the data are presented as mean $\pm S D(n=3)$ with asterisks indicating significant changes $\left({ }^{\star} P<0.05,{ }^{\star \star} P<0.01\right)$.

Compound $\mathrm{C}$ may be used as a molecular scaffold for the development of autoimmune therapy in the future.

\section{DISCUSSION}

Despite the cellular immune response to dsDNA plays an indispensable role in pathogen defense, abnormal response to dsDNA has been shown to be an important factor in the etiology of hyperinflammatory or autoimmune disorders, such as SLE (Pisetsky, 2016) and AGS (Crow et al., 2006) or Chilblain lupus (Rice et al., 2007). But so far, there is no effective therapy for these diseases. Compound $\mathrm{C}$ is a small molecule compound widely used as an inhibitor of AMPKs. In the present study, we find that Compound $\mathrm{C}$ can be used as an inhibitor of the DNAdependent cGAS-STING pathway. Our data demonstrate that after the HT-DNA transfection, the expression of IFN $\beta$ was significantly inhibited in human or mouse cells treated with Compound C. We also tested if Compound $\mathrm{C}$ was able to inhibit the activation of RNA-sensing pathway by using poly(I:C) treatment. However, we did not see the consistent effect and the Compound $\mathrm{C}$ effects on RNA-mediated immune responses seemed to be cell-type dependent. Particularly, we observed Compound C-mediated inhibition of the IFN $\beta$ mRNA expression induced by poly(I:C) only in the cells that express little or no cGAS and STING (Figure S2 and Figure S3), which needs to be further clarified in the future. 
A

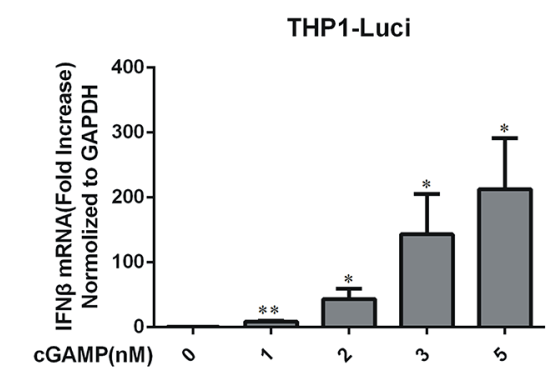

C

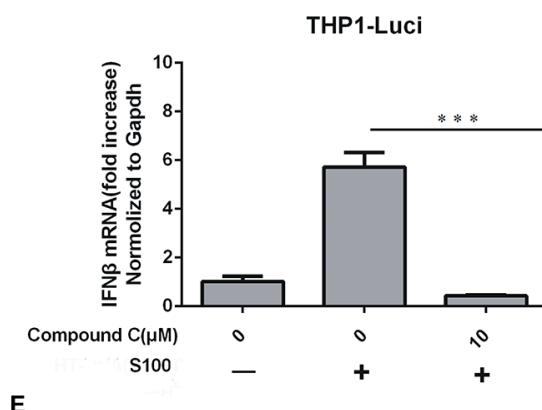

E

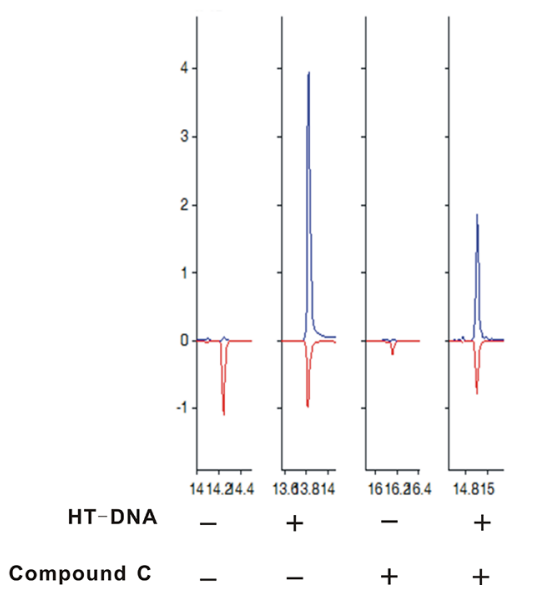

B

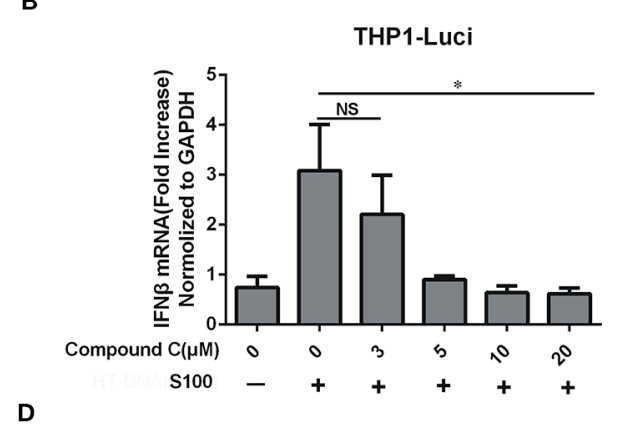

D

THP1-Luci

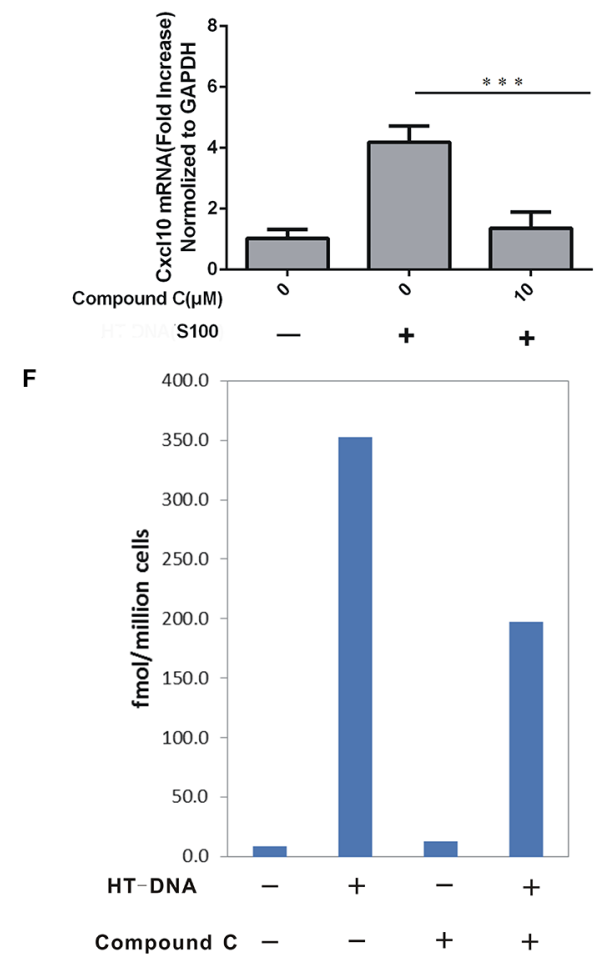

FIGURE 5 | Compound C lowered the cGAMP level. (A) RT-qPCR analyses of IFN $\beta$ induction in THP1-ISG-liciferase cells. The cells were treated with the increasing amounts of CGAMP. (B) RT-qPCR analyses of IFN $\beta$ induction in THP1-ISG-liciferase cells. The cells were treated with the S100 fractions which were extracted from the BJ cells transfected with HT-DNA after treated with indicated doses of Compound C for 1h. (C, D) RT-qPCR analyses of IFNB (C), CXCL10 (D) expression in THP1-ISG-liciferase cells treated with the S100 fractions which were extracted from the BJ cells transfected with HT-DNA after treated with indicated doses of Compound C for 1h. (E, F) LC-MS analyses of the content of CGAMP in the S100 fractions which were extracted from the BJ cells transfected with HT-DNA after treated with $10 \mu \mathrm{M}$ Compound $\mathrm{C}$. The experiments were performed at least three times. Data in bar graphs are presented as mean $\pm S D(n=3-5)$ with asterisks indicating significant changes (NS, Nonsignnificant, ${ }^{\star} P<0.05,{ }^{* \star} P<0.01,{ }^{\star \star *} P<0.001$ ).

In this study, since Compound $\mathrm{C}$ did not significantly affect cGAMP-induced INF $\beta$ production and it may work in the upstream of cGAMP. Indeed, in the experiments by testing the Compound $\mathrm{C}$ effects following TBK1 stimulation in the cells lacking cGAS-STING, we further demonstrate that the target of compound $\mathrm{C}$ is in the upstream of TBK1. We next tested if Compound $\mathrm{C}$ could directly affect the function of cGAS. However, Compound $\mathrm{C}$ did not decrease either the protein level of cGAS in the cells tested or the ATP consumption in in vitro cGAMP synthesis assay (Figure 6). In addition, MicroScale Thermophoresis (MST) experiments showed the binding affinity (Kd) of Compound C to the cGAS was $96.6 \mu \mathrm{M}$, but we were unable to solve the crystal structure of Compound $\mathrm{C}$ in complex with cGAS and dsDNA (data not shown). Therefore, Compound $\mathrm{C}$ does not directly bind to the cGAS active sites. Therefore, Compound $\mathrm{C}$ may inhibit the cGAS-mediated activites by inhibiting a certain upstream gene, a similar role as epigallocatechin gallate (EGCG). For example, EGCG is an 
A

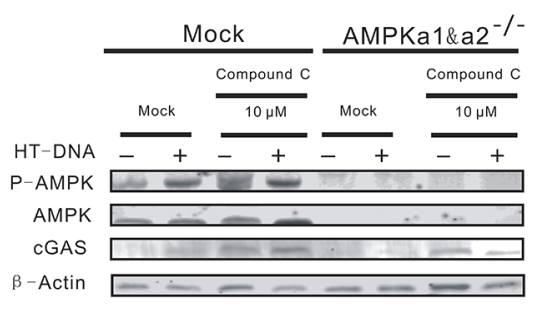

C

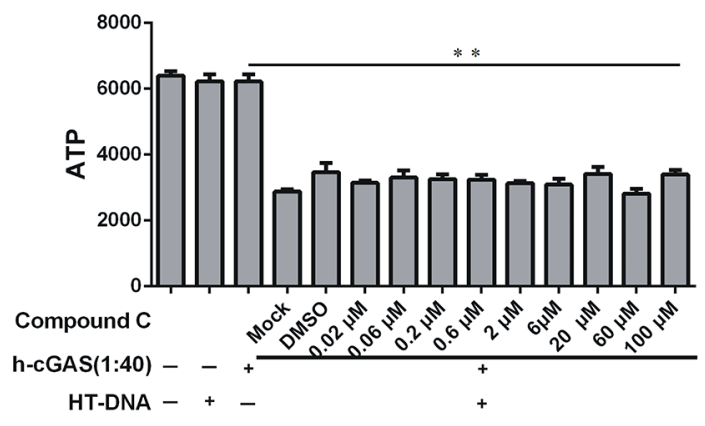

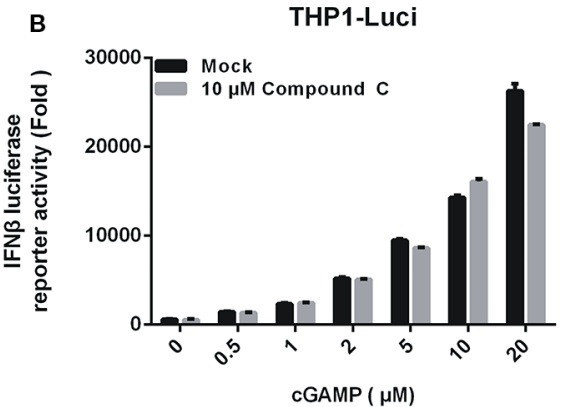

D

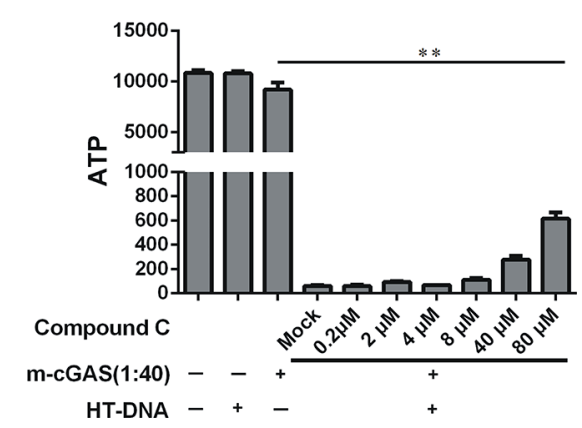

FIGURE 6 | The inhibitory effect of Compound C on cGAS-STING signaling was not dependent on the cGAS enzymatic activity. (A) Western blot analyses of pAMPK, AMPK, and cGAS expression in L929 wild-type and L929-AMPK ${ }^{-1-}$ cells. The cells were transfected with HT-DNA and poly (I:C) after treated with indicated doses of Compound C. (B) Enzyme-Linked Immunosorbent Assay (ELISA) analyses of IFN $\beta$ expression in THP1-Luci cells following stimulation by cGAMP at the different concentrations for $16 \mathrm{~h}$ with or without $5 \mu \mathrm{M}$ Compound $\mathrm{C}$ treatments. (C, D) The cGAS enzyme activity was evaluated by the (ATP consumption. The experiments were performed at least three times. Data in bar graphs are presented as mean $\pm S D(n=3-5)$ with asterisks indicating significant changes $\left({ }^{\star \star} P<0.01\right)$.

inhibitor for GTPase-activating protein SH3 domain-binding protein 1 (G3BP1), which is critical for the cGAS activation since it promotes the G3BP1-cGAS complex formation and enhances DNA binding of cGAS (Liu et al., 2018). Alternatively, Compound $\mathrm{C}$ may reduce cGAMP accumulation by facilitating cGAMP degradation. Indeed, our intracellular extraction of cGAMP and LC/MS experiments showed that the cells treated with Compound $\mathrm{C}$ caused a significant reduction of cGAMP after stimulation with HT-DNA (Figure 5). Interestingly, a recent study shows that Ecto-nucleotide pyrophosphatase phosphodiesterase 1 (ENPP1), preferentially hydrolyzes 2'3'-cGAMP, but not 3'3'-cGAMP, thereby negatively regulates the cGAS-STING pathway (Wang et al., 2018a). This preferential degradation is due to its binding to the ENPP1 active site in a conformation suitable for catalysis (Kato et al., 2018). Thus, it needs to be further clarified if Compound $C$ can affect cGAMP degradation by modulating ENPP1 activities.

It has been reported that cGAS is essential in activating the AMPK/ULK1 to suppress STING, which is responsible for triggering the dephosphorylation of AMPK T172 and activation of ULK1, so as to phosphorylate STING on S366 to impede its activity (Konno et al., 2013). Thus, the phosphorylation of AMPK may inhibit the cGAS-STING pathway. However, loss of AMPK function does not affect the IFN $\beta$ mRNA expression induced by HT-DNA or cGAMP in the present study since Compound C- mediated inhibition of the IFN $\beta$ mRNA expression is also found in the $\mathrm{L} 929-\mathrm{AMPK}^{-/-}$cell line, suggesting that the AMPK may not be responsible for Compound $\mathrm{C}$-mediated inhibition of the IFN $\beta$ mRNA expression, and some other targets might be involved.

In addition to AMPKs, ALKs which are the major kinases involved in BMP-mediated signaling is another major kinase family that can be inhibited by Compound C. Thus, ALKs may be a possible candidate that is involved in Compound C-mediated inhibition. To test this hypothesis, we generated the ALKs knockout cells and we found that the production of IFN $\beta$ was inhibited by the loss of ALKs when these gene knock-out cells were transfected with HT-DNA (data not shown). We currently work on this hypothesis but the data will not be included here.

Apart from AMPK and BMP signaling, Compound $\mathrm{C}$ has been shown to exert various "off-target" biological effects, such as inhibiting vascular endothelial growth factor type II receptor and inhibiting hypoxia-inducible factor-1 activation (Fraley et al., 2002; Emerling et al., 2007). By using the kinase inhibition profiling panel, Compound $\mathrm{C}$ has been found to inhibit a number of other kinases with similar or greater potencies (Bain et al., 2007). Therefore, we cannot exclude the other protein kinase pathways that may contribute to Compound Cmediated inhibition of the immune responses.

Due to the deficiency of Trex $1^{-1-}$ and DNaseII ${ }^{-1-}$ in mice, impaired aberrant DNA clearance causes severe autoimmune 
A

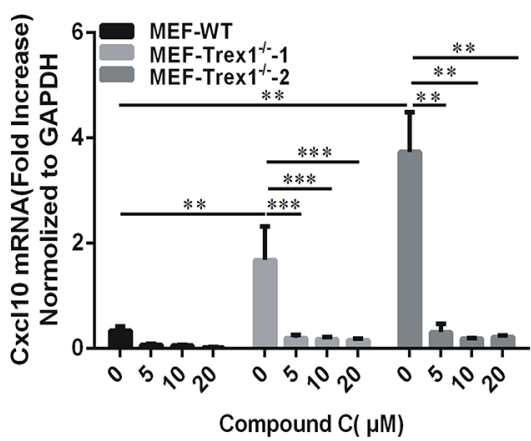

C

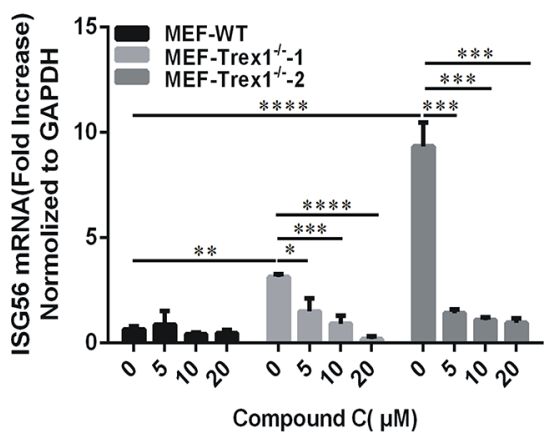

D
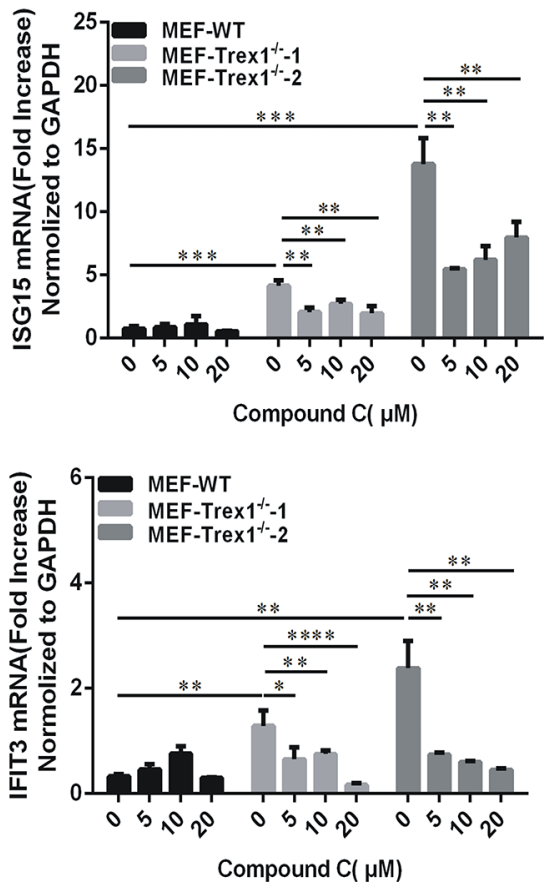

FIGURE 7 | Compound C is active in cells loss of Trex1 gene. (A-D) RT-qPCR analyses of CXCL10 (A), ISG15 (B), ISG56(C), and IFIT3 (D) expression in mouse embryonic fibroblast (MEF) wild-type and MEF-Trex $1^{-1-}$ cells. The cells were treated with indicated doses of Compound $\mathrm{C}$ for $3 \mathrm{~h}$. The experiments were performed at least three times. Data in bar graphs are presented as mean $\pm \mathrm{SD}(\mathrm{n}=3)$ with asterisks indicating significant changes $\left({ }^{\star} P<0.05,{ }^{\star \star} P<0.01\right.$, $\left.{ }^{\star \star \star} P<0.001,{ }^{\star \star \star \star} P<0.0001\right)$.

phenotypes, including inappropriate activation, continuous production of type I IFN and a high lethality (Napirei et al., 2000; Morita et al., 2004; Okabe et al., 2005; Yoshida et al., 2005). These autoimmune phenotypes can be rescued by genetic ablation of STING, IRF3 or the type I IFN receptor (Kawane et al., 2006; Stetson et al., 2008; Ahn et al., 2012; Gall et al., 2012; Ablasser et al., 2014; Gao et al., 2015; Gray et al., 2015). The abnormal activation of cGAS in autoimmune diseases caused by incomplete self-DNA clearance has also been demonstrated in Trex $1^{-/-}$and DNaseII ${ }^{-1-}$ mice. Activation of cGAS-STING results in an autoimmune phenotype in the mice with Trexl and DNaseII deletions. Deletion of cGAS or STING improves the survival and autoimmune phenotypes such as elevated ISG expression, production of autoantibodies of Trex1- or DNaseII-deficient mice by preventing cGAMP accumulation and ISGs expression (Gao et al., 2015; Motani et al., 2015). Therefore, keeping cGAS-STING function in line could be a potential therapeutic strategy for the diseases caused by reduced TREX1 activity, such as lupus. In our study, we showed the Compound $\mathrm{C}$ effects in autoimmune inhibition by using MEF$\mathrm{Trex}^{-/-}$cell lines. Therefore, Compound $\mathrm{C}$ may have potential therapeutic values for being used as a potent inhibitor of dsDNAinduced autoimmune activation, such as treating immune diseases caused by Trex1 deletion.
In summary, cGAS is an essential protein for the innate immune response to cytosolic DNAs and has been considered as a potential valuable target for the therapeutic development to improve the treatment of human autoimmune disorders. Compound $\mathrm{C}$ showed potent and selective inhibition of dsDNA-dependent pathway, which may shed light on developing the immunomodulatory therapeutic agents in treating cGAS-related human disorders.

\section{DATA AVAILABILITY STATEMENT}

All datasets generated for this study are included in the article/ Supplementary Material.

\section{ETHICS STATEMENT}

The animal experiments were performed under the Guide for the Care and Use of Laboratory Animals approved by Fujian Provincial Office for Managing Laboratory Animals and were overseen by the Fujian Normal University Animal Care and Use Committee. 


\section{AUTHOR CONTRIBUTIONS}

Conceptualization: QC. Methodology: JL, XL, ST, XZ. Validation: JL, ST, QL, SH. Formal analysis: JL, HW. Investigation: JL, HW, SC. Data curation: JL. Writing (original draft preparation): QC, JL, ST. Writing (review and editing): QC, JL, ST. Visualization: JL, XL. Supervision: QC. Project administration: QC. Funding acquisition: QC.

\section{FUNDING}

This research was supported by the Natural Science Foundation of the Fujian Province, China (Grant No. 2017J01621) and the Innovative Research Team Program II of Fujian Normal University in China (IRTL1703).

\section{REFERENCES}

Abe, T., and Barber, G. N. (2014). Cytosolic-DNA-mediated, STINGdependent proinflammatory gene induction necessitates canonical NF$\kappa \mathrm{B}$ activation through TBK1. J. Virol. 88 (10), 5328-5341. doi: 10.1128/ JVL00037-14

Abe, T., Harashima, A., Xia, T., Konno, H., Konno, K., Morales, A., et al. (2013). STING recognition of cytoplasmic DNA instigates cellular defense. Mol. Cell 50 (1), 5. doi: 10.1016/j.molcel.2013.01.039

Ablasser, A., Goldeck, M., Cavlar, T., Deimling, T., Witte, G., Röhl, I., et al. (2013). cGAS produces a 2 [prime]-5 [prime]-linked cyclic dinucleotide second messenger that activates STING. Nature 498 (7454), 380-384. doi: 10.1038/ nature 12306

Ablasser, A., Hemmerling, I., Schmid-Burgk, J. L., Behrendt, R., Roers, A., and Hornung, V. (2014). TREX1 deficiency triggers cell-autonomous immunity in a cGAS-dependent manner. J. Immunol. 192 (12), 5993-5997. doi: 10.4049/ jimmunol.1400737

Ahn, J., Gutman, D., Saijo, S., and Barber, G. N. (2012). STING manifests self DNAdependent inflammatory disease. Proc. Natl. Acad. Sci. 109 (47), 19386-19391. doi: 10.1073/pnas.1215006109

Bain, J., Plater, L., Elliott, M., Shpiro, N., Hastie, C. J., Mclauchlan, H., et al (2007). The selectivity of protein kinase inhibitors: a further update. Biochem. J. 408(3), 297-315. doi: 10.1042/BJ20070797

Cai, X., Chiu, Y.-H., and Chen, Z. J. (2014). The cGAS-cGAMP-STING pathway of cytosolic DNA sensing and signaling. Mol. Cell 54 (2), 289-296. doi: 10.1016/j.molcel.2014.03.040

Civril, F., Deimling, T., de Oliveira Mann, C. C., Ablasser, A., Moldt, M., Witte, G., et al. (2013). Structural mechanism of cytosolic DNA sensing by cGAS. Nature 498 (7454), 332-337. doi: 10.1038/nature12305

Crow, Y. J., Hayward, B. E., Parmar, R., Robins, P., Leitch, A., Ali, M., et al. (2006). Mutations in the gene encoding the $3^{\prime}-5^{\prime}$ DNA exonuclease TREX1 cause Aicardi-Goutières syndrome at the AGS1 locus. Nat. Genet. 38 (8), 917-920. doi: $10.1038 / \mathrm{ng} 1845$

Dasgupta, B., and Seibel, E. (2018). Compound C/Dorsomorphin: Its Use andMisuse as an AMPK Inhibitor. AMPK. (New York, NY: Humana Press) 2018, 195-202. doi: 10.1007/978-1-4939-7598-3

Diner, E. J., Burdette, D. L., Wilson, S. C., Monroe, K. M., Kellenberger, C. A., Hyodo, M., et al. (2013). The innate immune DNA sensor cGAS produces a noncanonical cyclic dinucleotide that activates human STING. Cell Rep. 3 (5), 1355-1361. doi: 10.1016/j.celrep.2013.05.009

Emerling, B. M., Viollet, B., Tormos, K. V., and Chandel, N. S. (2007). Compound C inhibits hypoxic activation of HIF-1 independent of AMPK. FEBS Lett. 581 (29), 5727-5731. doi: 10.1016/j.febslet.2007.11.038

Fraley, M. E., Rubino, R. S., Hoffman, W. F., Hambaugh, S. R., Arrington, K. L., Hungate, R. W., et al. (2002). Optimization of a pyrazolo[1,5-]pyrimidine class of KDR kinase inhibitors: improvements in physical properties enhance cellular activity and pharmacokinetics. Bioorg. Med. Chem. Lett. 12 (24), 3537-3541. doi: 10.1016/S0960-894X(02)00827-2

\section{ACKNOWLEDGMENTS}

We would like to thank Dr. Lijun Sun for his valuable advice and suggestions, Yajuan $\mathrm{Fu}$ and Zhang Lin for administrative assistance, and Dr. Daliang Li and the members of the Chen's laboratory for the technical assistance and helpful discussion.

\section{SUPPLEMENTARY MATERIAL}

The Supplementary Material for this article can be found online at: https://www.frontiersin.org/articles/10.3389/fphar.2020. 00088/full\#supplementary-material

Gall, A., Treuting, P., Elkon, K. B., Loo, Y.-M., Gale, M., Barber, G. N., et al. (2012). Autoimmunity initiates in nonhematopoietic cells and progresses via lymphocytes in an interferon-dependent autoimmune disease. Immunity 36 (1), 120-131. doi: 10.1016/j.immuni.2011.11.018

Gao, P., Ascano, M., Wu, Y., Barchet, W., Gaffney, B. L., Zillinger, T., et al. (2013). Cyclic [G $\left.\left(2^{\prime}, 5^{\prime}\right) \mathrm{pA}\left(3^{\prime}, 5^{\prime}\right) \mathrm{p}\right]$ is the metazoan second messenger produced by DNAactivated cyclic GMP-AMP synthase. Cell 153 (5), 1094-1107. doi: 10.1016/ j.cell.2013.04.046

Gao, D., Li, T., Li, X. D., Chen, X., Li, Q. Z., Wight-Carter, M., et al. (2015). Activation of cyclic GMP-AMP synthase by self-DNA causes autoimmune diseases. Proc. Natl. Acad. Sci. U. S. A 112 (42), E5699-E5705. doi: 10.1073/ pnas. 1516465112

Goubau, D., Deddouche, S., and Sousa, C. R. (2013). Cytosolic sensing of viruses. Immunity 38 (5), 855-869. doi: 10.1016/j.immuni.2013.05.007

Gray, E. E., Treuting, P. M., Woodward, J. J., and Stetson, D. B. (2015). Cutting edge: cGAS is required for lethal autoimmune disease in the trex1-deficient mouse model of Aicardi-Goutières syndrome. J. Immunol. 195 (5), 1939-1943. doi: 10.4049/jimmunol.1500969

Hall, J., Brault, A., Vincent, F., Weng, S., Wang, H., Dumlao, D., et al. (2017). Discovery of PF-06928215 as a high affinity inhibitor of cGAS enabled by a novel fluorescence polarization assay. PloS One 12 (9), e0184843. doi: 10.1371/ journal.pone.0184843

Ishikawa, H., and Barber, G. N. (2009). STING an endoplasmic reticulum adaptor that facilitates innate immune signaling. Nature 48 (1-2), 674. doi: 10.1016/ j.cyto.2009.07.543

Jin, J., Mullen, T. D., Hou, Q., Bielawski, J., Bielawska, A., Zhang, X., et al. (2009). AMPK inhibitor Compound $\mathrm{C}$ stimulates ceramide production and promotes Bax redistribution and apoptosis in MCF7 breast carcinoma cells 50, 12, 2389-2397. doi: 10.1194/jlr.M900119-JLR200

Kato, K., Nishimasu, H., Oikawa, D., Hirano, S., Hirano, H., Kasuya, G., et al. (2018). Structural insights into cGAMP degradation by Ecto-nucleotide pyrophosphatase phosphodiesterase 1. Nat. Commun. 9 (1), 4424. doi: 10.1038/s41467-018-06922-7

Kawane, K., Ohtani, M., Miwa, K., Kizawa, T., Kanbara, Y., Yoshioka, Y., et al. (2006). Chronic polyarthritis caused by mammalian DNA that escapes from degradation in macrophages. Nature 443 (7114), 998-1002. doi: 10.1038/ nature 05245

Kim, Y. M., Kim, M. Y., Kim, H. J., Roh, G. S., Ko, G. H., Seo, H. G., et al. (2011) Compound $\mathrm{C}$ independent of AMPK inhibits ICAM-1 and VCAM-1 expression in inflammatory stimulants-activated endothelial cells in vitro and in vivo. Atherosclerosis 219 (1), 57-64. doi: 10.1016/j.atherosclerosis. 2011.06.043

Konno, H., Konno, K., and Barber, G. N. (2013). Cyclic Di Nucleotides Trigger ULK1 (ATG1) Phosphorylation of STING to prevent sustained innate immune signaling. Cell 155 (3), 688-698. doi: 10.1016/j.cell.2013.09.049

Kranzusch, P. J., Lee, A. S.-Y., Berger, J. M., and Doudna, J. A. (2013). Structure of human cGAS reveals a conserved family of second-messenger enzymes in innate immunity. Cell Rep. 3 (5), 1362-1368. doi: 10.1016/j.celrep.2013.05.008 
Li, X., Shu, C., Yi, G., Chaton, C. T., Shelton, C. L., Diao, J., et al. (2013). Cyclic GMPAMP synthase is activated by double-stranded DNA-induced oligomerization. Immunity 39 (6), 1019-1031. doi: 10.1016/j.immuni.2013.10.019

Liu, S., Cai, X., Wu, J., Cong, Q., Chen, X., Li, T., et al. (2015). Phosphorylation of innate immune adaptor proteins MAVS, STING, and TRIF induces IRF3 activation. Science 347 (6227), 26-30. doi: 10.1126/science.aaa2630

Liu, Z.-S., Cai, H., Xue, W., Wang, M., Xia, T., Li, W.-J., et al. (2018). G3BP1 promotes DNA binding and activation of cGAS. Nat. Immunol. 20 (1), 18-28. doi: 10.1038/s41590-018-0262-4

Luteijn, R. D., Zaver, S. A., Gowen, B. G., Wyman, S. K., Garelis, N. E., Onia, L., et al. (2019). SLC19A1 transports immunoreactive cyclic dinucleotides. Nature 573 (7774), 434-438. doi: 10.1038/s41586-019-1553-0

Morita, M., Stamp, G., Robins, P., Dulic, A., Rosewell, I., Hrivnak, G., et al. (2004). Genetargeted mice lacking the Trexl (DNase III) $3^{\prime} \rightarrow 5^{\prime}$ DNA exonuclease develop inflammatory myocarditis. Mol. Cell. Biol. 24 (15), 6719-6727. doi: 10.1128/ MCB.24.15.6719-6727.2004

Motani, K., Ito, S., and Nagata, S. (2015). DNA-mediated cyclic GMP-AMP synthase-dependent and-independent regulation of innate immune responses. J. Immunol. 194 (10), 4914-4923. doi: 10.4049/jimmunol.1402705

Nan, Y., Regalado-Magdos, A. D., Stiggelbout, B., Min, L. K., and Lieberman, J. (2010). The cytosolic exonuclease TREX1 inhibits the innate immune response to HIV-1. Nat. Immunol. 11 (11), 1005-1013. doi: 10.1038/ni.1941

Napirei, M., Karsunky, H., Zevnik, B., Stephan, H., and Möröy, T. (2000). Features of systemic lupus erythematosus in Dnase1-deficient mice. Nat. Genet. 25 (2), 177-181. doi: 10.1038/76032

O'Neill, L. A., Golenbock, D., and Bowie, A. G. (2013). The history of Toll-like receptors [mdash] redefining innate immunity. Nat. Rev. Immunol. 13 (6), 453-460. doi: 10.1038/nri3446

Okabe, Y., Kawane, K., Akira, S., Taniguchi, T., and Nagata, S. (2005). Toll-like receptor-independent gene induction program activated by mammalian DNA escaped from apoptotic DNA degradation. J. Exp. Med. 202 (10), 1333-1339. doi: $10.1084 /$ jem.20051654

Pandey, S., Kawai, T., and Akira, S. (2015). Microbial sensing by Toll-like receptors and intracellular nucleic acid sensors. Cold Spring Harbor Perspect. In Biol. 7 (1), a016246. doi: 10.1101/cshperspect.a016246

Pisetsky, D. S. (2016). Anti-DNA antibodies [mdash] quintessential biomarkers of SLE. Nat. Rev. Rheumatol. 12 (2), 102. doi: 10.1038/nrrheum.2015.151

Rice, G., Newman, W. G., Dean, J., Patrick, T., Parmar, R., Flintoff, K., et al. (2007). Heterozygous mutations in TREX1 cause familial chilblain lupus and dominant Aicardi-Goutieres syndrome. Am. J. Hum. Genet. 80 (4), 811. doi: $10.1086 / 513443$

Saito, S., Furuno, A., Sakurai, J., Park, H. R., Shin-Ya, K., and Tomida, A. (2012). Compound $\mathrm{C}$ prevents the unfolded protein response during glucose deprivation through a mechanism independent of AMPK and BMP signaling. PloS One 7 (9), e45845. doi: 10.1371/journal.pone.0045845

Schoggins, J. W., MacDuff, D. A., Imanaka, N., Gainey, M. D., Shrestha, B., Eitson, J. L., et al. (2014). Pan-viral specificity of IFN-induced genes reveals new roles for cGAS in innate immunity. Nature 505 (7485), 691-695. doi: 10.1038/nature12862

Seo, K., Seo, S., Ki, S. H., and Sang, M. S. (2016). Compound C increases Sestrin2 expression via Mitochondria-dependent ROS production. Biol. Pharm. Bull. 39 (5), 799-806. doi: 10.1248/bpb.b15-00938

Stetson, D. B., Ko, J. S., Heidmann, T., and Medzhitov, R. (2008). Trex1 prevents cell-intrinsic initiation of autoimmunity. Cell 134 (4), 587-598. doi: 10.1016/ j.cell.2008.06.032
Takeuchi, O., and Akira, S. (2010). Pattern recognition receptors and inflammation. Cell 140 (6), 805-820. doi: 10.1016/j.cell.2010.01.022

Vincent, J., Adura, C., Gao, P., Luz, A., Lama, L., Asano, Y., et al. (2017). Small molecule inhibition of cGAS reduces interferon expression in primary macrophages from autoimmune mice. Nat. Commun. 8 (1), 1-13. doi: 10.1038/s41467-017-00833-9

Wang, J., Lu, S. F., Wan, B., Ming, S. L., Li, G. L., Su, B. Q., et al. (2018a). Maintenance of cyclic GMP-AMP homeostasis by ENPP1 is involved in pseudorabies virus infection. Mol. Immunol. 9 (5), 56-63. doi: 10.1016/ j.molimm.2018.01.008

Wang, M., Sooreshjani, M., Mikek, C., OpokuTemeng, C., and Sintim, H. (2018b). Suramin potently inhibits cGAMP synthase, cGAS, in THP1 cells to modulate IFN- $\beta$ levels. Future Med. Chem. 10 (11), 1301-1317. doi: 10.4155/fmc-20170322

$\mathrm{Wu}, \mathrm{J}$., and Chen, Z. J. (2014). Innate immune sensing and signaling of cytosolic nucleic acids. Annu. Rev. Immunol. 32 (1), 461-488. doi: 10.1146/annurevimmunol-032713-120156

Wu, J., Sun, L., Chen, X., Du, F., Shi, H., Chen, C., et al. (2013). Cyclic-GMP-amp is an endogenous second messenger in innate immune signaling by Cytosolic DNA. Science 339 (6121), 826-830. doi: 10.1126/science.1229963

Xiao, T. S., and Fitzgerald, K. A. (2013). The cGAS-STING pathway for DNA sensing. Mol. Cell 51 (2), 135-139. doi: 10.1016/j.molcel.2013.07.004

Xiao, N., Wei, J., Xu, S., Du, H., Huang, M., Zhang, S., et al. (2019). cGAS activation causes lupus-like autoimmune disorders in a TREX1 mutant mouse model. J. Autoimmun. 100, 84-94. doi: 10.1016/j.jaut.2019.03.001

Yoshida, H., Okabe, Y., Kawane, K., Fukuyama, H., and Nagata, S. (2005). Lethal anemia caused by interferon- $\beta$ produced in mouse embryos carrying undigested DNA. Nature 6 (1), 49-56. doi: 10.1038/ni1146

Yun-Gui, Y., Tomas, L., and Barnes, D. E. (2007). Trexl exonuclease degrades ssDNA to prevent chronic checkpoint activation and autoimmune disease. Cell 131 (5), 873-886. doi: 10.1016/j.cell.2007.10.017

Zhang, X., Shi, H., Wu, J., Zhang, X., Sun, L., Chen, C., et al. (2013). Cyclic GMPAMP containing mixed phosphodiester linkages is an endogenous highaffinity ligand for STING. Mol. Cell 51 (2), 226-235. doi: 10.1016/ j.molcel.2013.05.022

Zhang, X., Wu, J., Du, F., Xu, H., Sun, L., Chen, Z., et al. (2014). The cytosolic DNA sensor cGAS forms an oligomeric complex with DNA and undergoes switchlike conformational changes in the activation loop. Cell Rep. 6 (3), 421-430. doi: 10.1016/j.celrep.2014.01.003

Zhou, G., Myers, R., Li, Y., Chen, Y., Shen, X., Fenyk-Melody, J., et al. (2001). Role of AMP-activated protein kinase in mechanism of metformin action. J. Clin. Invest. 108 (8), 1167-1174. doi: 10.1172/JCI13505

Conflict of Interest: The authors declare that the research was conducted in the absence of any commercial or financial relationships that could be construed as a potential conflict of interest.

Copyright $\odot 2020$ Lai, Luo, Tian, Zhang, Huang, Wang, Li, Cai and Chen. This is an open-access article distributed under the terms of the Creative Commons Attribution License (CC BY). The use, distribution or reproduction in other forums is permitted, provided the original author(s) and the copyright owner(s) are credited and that the original publication in this journal is cited, in accordance with accepted academic practice. No use, distribution or reproduction is permitted which does not comply with these terms. 